\section{Thomas Alured Faunce,}

BA LLB(Hons) B Med. PhD.

Australian Research Council Future Fellow

Associate Professor: Medical School and

College of Law (joint appointment)
$\mathrm{Rm} 284$

College of Law, Bdg 5

Fellows Road, Acton

Canberra ACT 0200

T: +61261253563

F: +61262490103

E: Thomas.Faunce@anu.edu.au

9 February 2011

\title{
International Conference: Towards Global Artificial Photosynthesis: Energy, Nanochemistry and Governance (GAP I)
}

This international conference will be held in Australia at Lord Howe Island 14-18 August 2011. This will be the first conference to discuss and begin to enunciate the principles that should underpin global governance and coordination of artificial photosynthesis (GAP I).

The aim of the conference is to foster international colloborations and strategies for funding in 5 key areas of global artificial photosynthesis: (1) governance and regulatory arrangement (2) energy capture (3) energy conversion and storage (4) carbon fixation and (5) modified and synthetic biological processes.

Confirmed speakers include:

1) Prof. Peidong Yang, Professor Department of Chemistry, University of California

Department Head Joint Center for Artificial Photosynthesis

2) Prof. Daniel G. Nocera

Henry Dreyfus Professor of Energy and Professor of Chemistry MIT

3) Prof. Gary Brudvig

Eugene Higgins Professor of Chemistry. Professor of Molecular Biophysics \& Biochemistry

Department of Chemistry Yale University

4) Prof. Eva-Mari Aro Molecular Plant Biology Dept. of Biochemistry and Food Chemistry

University of Turku Finland.

The conference will be run Gordon style with morning and early evening talks and afternoons off. Conference details and registration information will appear at the following website. Special low registration rates apply for $\mathrm{PhD}$ scholars and post-docs

http://law.anu.edu.au/coast/tgap/conf.htm

The organising committee includes: Assoc. Prof. Thomas Faunce, Prof Ron Pace, Prof Elmars Krausz, Prof Fred Chow, Prof Warwick Hillier, Prof David Officer and Prof Rob Stranger.

Yours Sincerely

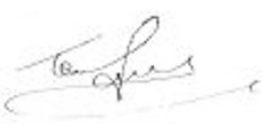

Associate Professor Thomas Faunce 